\title{
El ethos heroico en el Último Discurso de Salvador Allende
}

\section{The heroic ethos in Salvador Allende's Last Speech}

\author{
YASNA ROLDÁN VALDERRAMA \\ ${ }^{a}$ Universidad Austral de Chile, Facultad de Filosofía y Humanidades. \\ Correo electrónico: yasnaroldan@uach.cl
}

En este artículo se analiza desde la Lingüística Sistémico Funcional (LSF) el Último Discurso de Salvador Allende antes de su muerte. Mediante el análisis de la transitividad y el modo (Halliday y Matthiessen 2004), además de la identificación de los mecanismos de representación discursiva (van Leuween 1996, 2008), el análisis lingüístico propuesto se focaliza en la manera en que se construye el ethos discursivo. Los resultados muestran que el ethos se estructura en torno al emisor como Actor de procesos materiales y Hablante de procesos verbales, todo reforzado mediante recursos de somatización y abstracción. Además, en este discurso, la construcción del ethos comparte algunos tópicos del ethos militante (Montero 2007), pero en su particularidad histórica toma el tópico de la heroicidad y lo vuelve central en la construcción de un ethos heroico.

Palabras claves: retórica, discurso presidencial, ethos discursivo, representaciones sociales, Lingüística Sistémico Funcional.

This article analyzes from a Systemic Functional Linguistics standpoint (SFL) the last speech of Salvador Allende before his death. By means of transitivity and mood analysis (Halliday and Matthiessen 2004), as well as through identification of mechanisms of discursive representation (van Leuween 1996, 2008), the linguistic analysis we propose focuses on how discoursive ethos is constructed. The results show that ethos is built around the sender as an Actor of material processes and Speaker of verbal processes, all enhanced by somatization and abstraction resources. Furthermore, in this speech genre the construction of ethos shares some topics with the militant ethos (Montero 2007), but in its historical particularity takes the topic of heroism and turns it into a key element to the construction of a heroic ethos.

Key words: rhetoric, presidential speech, discursive ethos, social representations, Systemic Functional Linguistics. 


\section{INTRODUCCIÓN}

¿Qué podría decir en una sola palabra,
en unas pocas palabras que dejara huella en todos sus rostros
y les hiciera despertar?

Ray Bradbury, Fahrenheit 451

En Chile se ha desarrollado un creciente interés por el análisis de los discursos presidenciales desde diversas perspectivas metodológicas y con distintos propósitos (Berardi 1996, 2005; Burgueño 2006; Oyarzo, 2007; Roldán 2008, 2011, 2014). Algunas de estas investigaciones se acercan a los estudios del ethos, por ejemplo, Burdach y Ross (2005) se centran en el análisis de la construcción discursiva de la voz del expresidente Ricardo Lagos como enunciador y Segovia (2012) estudia la construcción de la imagen de sí mismo en los discursos de campaña de Ricardo Lagos y Michelle Bachelet. En Brasil, Barros y Moreira (2011) y Pereira (2012) se interesan por el ethos discursivo de Dilma Rousseff. En Argentina, encontramos los estudios de Dagatti (2012) referidos al ethos gubernamental de Néstor Kirchner y los de Montero $(2007,2012)$ que analiza las características discursivas del ethos militante en el discurso presidencial de Kirchner. Romano (2010), Vitale (2013) y Maizels (2014) estudian el ethos en discursos de la presidenta Cristina Fernández. Además, Vitale (2014) aporta un interesante estudio acerca del ethos femenino de Bachelet, Fernández y Rousseff, primeras mujeres presidentas en Chile, Argentina y Brasil, respectivamente. Siguiendo esta línea de investigación, me interesa analizar el ethos discursivo en el Último Discurso de Salvador Allende.

La muerte del presidente Allende en el Palacio de La Moneda el 11 de septiembre de 1973 ha sido por mucho tiempo un hecho controversial en cuanto algunos sectores de la sociedad chilena e internacional cuestionaron desde el principio la versión del suicidio. Para algunos el presidente fue asesinado, mientras que otros sostienen la tesis de un suicidio asistido. La polémica se suscita fundamentalmente, porque no hubo testigos de la muerte de Allende y porque su cuerpo fue enterrado el 12 de septiembre de 1973 de manera secreta y en una tumba anónima en Viña del Mar (Veneros 2003).

Ante la incertidumbre permanente y el cuestionamiento de la versión oficial, en el año 2011, los restos del presidenteSalvador Allende fueron exhumados y sometidos a peritajes forenses realizados por el Servicio Médico Legal de Chile en conjunto con expertos internacionales. Las diligencias se llevaron a cabo con la finalidad de corroborar mediante análisis morfológicos y biológicos la identidad del cadáver y establecer jurídica y biológicamente las circunstancias de la muerte. Los análisis antropológicos, dentales y de $\mathrm{ADN}$ confirmaron la identidad del presidente y el análisis tanatológico concluyó que la causa de la muerte corresponde a un suicidio. ${ }^{1}$

\footnotetext{
${ }^{1}$ Las conclusiones de los peritajes realizados al cuerpo de Salvador Allende se encuentran disponibles en el Informe de Exhumación publicado por la Fundación Salvador Allende en su página web: http://www. fundacionsalvadorallende.cl/wp/wp-content/uploads/2011/07/info-SML_Pdte-Allende.pdf
} 
En esta investigación presento el análisis del Último discurso de Salvador Allende ${ }^{2}$ entendido como un hito histórico, pues se trata del último discurso pronunciado por el presidente antes de su muerte, hecho que marca el fin de un gobierno democrático y el inicio de una dictadura militar de 17 años en Chile. Al respecto, me interesa focalizar el análisis lingüístico en la manera en que Allende se refiere a sí mismo en el discurso, es decir, precisar la manera en que construye el ethos discursivo para explicar la relación entre la construcción discursiva del ethos y la circunstancia de la muerte del presidente. Por estar esta alocución estructurada discursivamente como la última, no solo de un periodo de gobierno si no como la última de su vida hay en ella alusiones a la muerte inminente y al suicidio. Se presenta, por tanto, como un texto que contiene pistas sobre el carácter del enunciador y las razones que justifican la decisión de suicidarse. De este modo el acercamiento a la construcción discursiva de sí mismo se plantea en relación con el análisis de la transitividad, la modalidad y la recontextualización o representación discursiva como los recursos que configuran la construcción retórica del ethos. Así, el ethos discursivo como categoría retórica se analiza en función de las elecciones de los procesos y la participación del hablante en ellos, la manera en que se utilizan las categorías del modo para matizar las acciones y la recontextualización como la forma de construcción del yo.

\section{El Ethos y La RePRESENTACIÓN DE LOS ACTORES SOCIALES EN EL DISCURSO}

Los eventos sociales y los actores que participan en ellos están enmarcados histórica y culturalmente. Normalmente, los eventos se reflejan en multiplicidad de textos que despliegan estrategias diversas para representarlos discursivamente. En el caso del discurso lingüístico, por ejemplo, confluyen en este, el uso de figuras retóricas, de estrategias argumentativas, de procedimientos de legitimación o deslegitimación de los agentes como del discurso mismo, elección de estructuras sintáctico-semánticas y gestión de la agentividad. De este modo, los eventos sociales y los actores involucrados tienen su correlato en el discurso y en este se pueden apreciar diferentes construcciones o representaciones según sea la interpretación de la realidad que haga el productor del discurso.

Dentro de los discursos sociales relevantes y de los juegos de representaciones es interesante, por cierto, ubicar el discurso de naturaleza lingüística, especialmente aquel que es consecuencia de la actividad política de un grupo en particular,

como todo comportamiento social, la acción política no es comprensible fuera del orden simbólico que la genera y del universo imaginario que ella misma engendra dentro de un campo determinado de relaciones sociales. Ahora bien, el único camino para acceder a los mecanismos imaginarios y simbólicos asociados al sentido de la acción es el análisis de los discursos sociales (Sigal y Verón 2003: 15).

\footnotetext{
${ }^{2}$ Tanto el texto como el audio del Último discurso de Salvador Allende se encuentran disponibles en distintos sitios de Internet.
} 
El discurso político, como producto, es la representación de un complejo entramado social, pero también de hechos políticos e históricos específicos. Entre los eventos del discurso político, siempre resulta relevante determinar la configuración que hace el que habla acerca de sí mismo y cómo representa a aquellos a quienes se dirige,

enunciador y destinatario son entidades del imaginario: son las imágenes de la fuente y el destino, construidas por el discurso mismo. La distinción es importante, puesto que un emisor, en diferentes momentos, puede construir imágenes muy diferentes de sí mismo (Sigal y Verón 2003: 23).

En este sentido, las representaciones sociales corresponden al modo de presentar discursivamente a los actores sociales involucrados en relaciones de tipo social. Estos actores pueden adoptar una actitud pasiva o, por el contrario, actuar como modificadores de su propio entorno. Hay que distinguir, sin embargo, entre los roles de los actores sociales en el contexto social e histórico en el que interactúan y la representación que se hace de ellos en el discurso. De esta manera, se entiende que las representaciones sociales son "construcciones simbólicas individuales y/o colectivas a las que los sujetos apelan o que los sujetos crean para interpretar el mundo, para reflexionar sobre su propia situación y la de los demás y para determinar el alcance y la posibilidad de su acción histórica" (Vasilachis 2003: 102); mientras que en el discurso lingüístico confluyen estrategias diversas para afrontar de una manera particular y motivada las diferentes representaciones de los actores sociales y de los eventos sociales. Esto conlleva distintas representaciones textuales de los fenómenos, además de que un mismo actor social o un mismo evento pueden ser representados de distintas formas.

En relación con el discurso político, que es el tema de esta investigación, destacan en él la construcción y representación de conflictos, de luchas sociales, de cambios históricos y políticos, por un lado, y el proceso de constitución de los sujetos políticos en el discurso, por otro. Al respecto, debemos recordar que en el discurso se construyen primordialmente dos entidades enunciativas correspondientes a "quien habla" y a "quien se le habla" además de la serie de grupos sociales o la serie de colectivos que también conllevan construcciones desde una perspectiva política discursiva.

Debido a que los sujetos participantes en política son siempre reconocidos en el discurso político mediante las representaciones discursivas que se hace de ellos, las representaciones que nos interesa indagar en esta oportunidad se corresponden con la autorepresentación que corresponde al interés de legitimación del hablante en su discurso mediante construcciones de la propia identidad discursiva y del posicionamiento del "yo" como ser individual o el "nosotros" como ser colectivo.

La manera en que el orador se inscribe discursivamente en su discurso se corresponde con la construcción discursiva del ethos entendido como "la imagen que el orador construye y proyecta de sí mismo en su discurso, imagen que contribuye a asegurar su autoridad, su eficacia y su credibilidad" (Montero 2012: 228). La construcción del ethos favorece los propósitos de persuasión del discurso en cuanto se elabora mediante el despliegue de los ethe 
o los atributos del orador (Barthes 1993) que buscan causar una impresión favorable en el auditorio. Al mismo tiempo que los ethe definen al orador en la imagen positiva de sí mismo, la disposición del ethos se reafirma por lo que el orador no es, es decir, "el orador enuncia una información y al mismo tiempo dice: yo soy éste; yo no soy aquél" (Barthes 1993: 143).

Entendido el ethos discursivo como la construcción de una imagen, "los actores sociales tienden a pensarse y representarse a sí mismos tal como son pensados y representados por los que tienen el poder de decir" (Vasilachis 1997: 144) de modo tal que las representaciones de los actores sociales son constitutivas de imágenes que sobrepasan el ámbito del discurso y pueden instalarse en el imaginario colectivo, sin olvidar por cierto que "los sujetos se sirven de la palabra y el discurso para poder representarse a sí mismos, pero es una representación que necesita ser verificada o sancionada por el otro" (Gutiérrez Castańeda 1999: 189). Por tanto, estas imágenes se plantean como políticamente negociables ya que "ni toda imagen ha de ser reconocida por los otros, ni los otros han de aceptar en todos los casos la interpretación o imagen que se les atribuye" (Gutiérrez Castañeda 1999: 194). Se entiende, entonces, a los sujetos políticos del discurso como entidades inestables y precarias susceptibles de cambiar en el tiempo o en distintos contextos discursivos "abiertas al debate y a nuevas rearticulaciones como cualquier construcción discursiva” (Gutiérrez Castańeda 1999: 199).

En el marco de una emisión discursiva única y dramática como el discurso pronunciado por el líder que defiende con su vida los ideales democráticos de su gobierno, es particularmente interesante poder definir el ethos discursivo que sustenta su imagen y que le otorga coherencia a la decisión de no rendirse frente a los golpistas. Más aún cuando se considera que el ethos es indisociable de la escena de enunciación en la cual se produce, entendida esta como la configuración socio-histórica que define los modos de legitimación que se producen en el discurso emitido en una situación particular, de modo tal que cada discurso instituye en sí mismo la situación que lo hace pertinente (Maingueneau 1996) y que justifica la configuración particular del ethos.

Como hemos visto, la imagen del sujeto político se corresponde con el despliegue de un ethos que se construye discursivamente desde que se designa en el enunciado por las marcas de primera persona y que se refuerza con la construcción de una imagen favorable de sí mismo con la intención de seducir al oyente y captar su benevolencia (Ducrot 1999). A lo anterior hay que agregar además la doble dimensión del ethos, pues el ethos construido en el discurso se apoya en elementos preexistentes como los actos previos o la autoridad que le confiere al orador una cierta posición o rango. La fuerza del discurso no solo se apoya en la configuración del 'yo' designado en la alocución en cuanto este puede remitir a entidades previas del mismo sujeto o incluso configurar proyecciones de sí mismo. Este ethos prediscursivo o

ethos previo se elabora sobre la base del rol que cumple el orador en el espacio social (...) pero también sobre la base de la representación colectiva del estereotipo que circula sobre su persona. Precede a la toma de la palabra y la condiciona parcialmente (Amossy 1999: 7). 
El ethos previo puede dejar huellas en el discurso susceptibles de rastrear, pero en este caso, centramos el análisis en los recursos léxico-semánticos y las estrategias discursivas que configuran el ethos discursivo, por lo que no integramos la imagen previa del orador.

Por último, resulta particularmente interesante la categoría de análisis propuesta por Montero en relación con la descripción de los tópicos que configuran el ethos militante. En el análisis de Montero (2007), se configura el ethos presidencial de Néstor Kirchner en relación con la reivindicación en el discurso "de la memoria de los jóvenes militantes peronistas de los años setenta, de la convicción de un tiempo y un modo específico de ejercer la política que reenvía a la militancia setentista" (Montero 2007: 92). Para ello, la autora determina tópicos recurrentes que configuran el ethos militante, entre ellos la heroicidad; la juventud maravillosa; las convicciones y los sueños; la politica como lucha, batalla o epopeya; la primacia de la politica y el antiliberalismo; las convicciones y los sueños; la intransigencia y la no neutralidad, y el militante como hombre común. Pareciera ser esta una categorización plausible desde la cual acercarse al ethos discursivo del Último discurso de Salvador Allende.

\section{FUNDAMENTOS TEÓRICO-METODOLÓGICOS: LINGÜÍSTICA SISTÉMICO FUNCIONAL Y PROPUESTA SOCIO-SEMIÓtica de VAN LeEUWEN}

La Lingüística Sistémico Funcional (LSF) conjuga la perspectiva semántica y la gramatical, porque considera al texto como una unidad esencialmente semántica cuyos significados se realizan mediante la elección de palabras y estructuras. Por lo tanto, la teoría da cuenta de cómo las elecciones construyen significado, esto es, una descripción gramatical que explicita el significado del texto. Así descrita, la gramática funcional está basada en el sistema como un todo y es una interpretación de las formas lingüísticas (Halliday 1994). En este sentido, se entiende el lenguaje como un recurso para construir significado y el significado reside en los patrones sistemáticos de elección (Halliday y Matthiessen 2004).

Así, la LSF centra su análisis en el lenguaje como discurso, en su contexto de producción o contexto social y en sus conexiones con el potencial semiótico del entorno cultural; de este modo, el análisis permite estudiar el lenguaje en uso y en su constitución en discurso como práctica social. Se entiende de esta manera que el lenguaje, como todo sistema de comunicación humana, representa y comunica hechos, estados y percepciones; que también representa y comunica aspectos relevantes de las relaciones sociales de los participantes de la comunicación, y que permite la producción de mensajes coherentes internamente en su configuración textual y externamente en relación con el entorno (Kress, Leite-García y van Leeuwen 2000).

En el enfoque del análisis de la LSF, las funciones básicas del lenguaje en relación con el entorno social consisten, por un lado, en construir sentido acerca de las experiencias, donde se aprecia el lenguaje como representación de la realidad; y, por otro lado, en actuar en las relaciones sociales visto el lenguaje como acción o como referencia a los roles de los participantes en el intercambio lingüístico (Halliday y Matthiessen 2004). Estos significados 
que se corresponden con las metafunciones ideacional e interpersonal respectivamente no constituyen niveles de significado disociados, al contrario, tanto el significado ideacional como el significado interpersonal se despliegan simultáneamente en la cláusula o en el texto.

La metafunción ideacional se refiere al significado potencial que manifiesta el hablante como observador de su entorno, por lo que corresponde a la representación de la realidad y al uso del lenguaje para manifestar las referencias acerca del mundo. Mediante el lenguaje, el hablante codifica su experiencia individual como miembro de la cultura (Halliday 1978) y alude, por tanto, a los significados relacionados con dicha experiencia. El significado experiencial de la metafunción ideacional del lenguaje se entiende como el significado que "expresa la experiencia humana como un "proceso" en el que interviene un "actor" como participante activo y las "circunstancias" de ese proceso" (Ghio y Fernández 2008: 92). Específicamente, son los actores sociales los que se relacionan con la dimensión experiencial de la metafunción ideacional de modo que los procesos y los participantes se representan en la cláusula como configuración de la propia experiencia a partir de la cual se construye lingüísticamente el mundo. En el análisis de la transitividad se pueden determinar tipos de procesos, tipos de participantes y tipos de circunstancias.

La metafunción interpersonal corresponde al significado potencial del hablante para introducirse a sí mismo y a su interlocutor en su texto. En este caso, el sistema gramatical que proyecta el significado de intercambio o interacción es el sistema de modo (Halliday y Matthiessen 2004; Ghio y Fernández, 2008). En este sistema, el hablante adopta un rol y le asigna al oyente un rol complementario los cuales van a depender de la elección del modo de la cláusula y los roles básicos que asumen los hablantes: dar o requerir información, bienes o servicios (Eggins 2002), según se trate de proposiciones o propuestas, respectivamente (Halliday y Matthiessen 2004). Lo esencial en este caso es centrar el análisis en la forma verbal (Quiroz 2008), pues en español el sujeto puede estar elidido con lo cual lo fundamental de la negociación (tiempo y modo) se encuentra en la desinencia del verbo. De esta forma verbal, interesa en esta ocasión la referencia modal a lo probable o improbable en las proposiciones, y a lo deseable y no deseable en las propuestas; además, se considera la polaridad en las formas de positivo o negativo que condicionan la gradualidad de las acciones.

El análisis del sistema de transitividad y del sistema de modo se puede complementar estudiando las formas en que se representan discursivamente los actores sociales de acuerdo con la propuesta socio-semiótica de van Leeuwen $(1996,2008)$. El inventario propuesto por este autor da cuenta de esta representación discursiva, es decir, cómo se realiza lingüísticamente entendiendo que cada elección de representación tiene su especificación lingüística o retórica. De este modo, su propuesta considera las categorías relevantes para investigar la representación de los actores sociales en el discurso y a cada una de ellas va asociando recursos lingüísticos característicos, sin que esto signifique necesariamente una relación biunívoca entre la representación social y su codificación en el lenguaje. Este proceso de recontextualización implica transformaciones, no siempre transparentes, como que los participantes pueden ser nombrados o suprimidos en el discurso. Si la elección es nombrarlos, 
estos pueden ser representados con recursos de personalización o impersonalización. Los actores sociales personalizados en el discurso pueden aparecer de forma particular o general, individual o colectivamente. También pueden estar determinados por distintos recursos como la categorización por funcionalización o identificación, la nominación con distintos grados de formalidad o alusiones a los títulos (titulación), etc. Cuando los actores sociales son impersonalizados, se representan por nombres abstractos o por sustantivos concretos que no implican el rasgo +humano y hay dos formas de manifestar la impersonalización, por abstracción y por objetivación. Por medio de la abstracción se ponen de relieve significados o cualidades que pueden ser asignados a los actores, por ejemplo, pobre, negro, trabajador no calificado, etc. En cambio, la objetivación se refiere a la representación por referencia a un lugar o cosa estrechamente relacionada con la persona, por lo tanto, se trata de una referencia metonímica que se desarrolla en cuatro subtipos: espacialización, autonomismo, instrumentalización y somatización.

\section{Metodología: desde el CONTEXTO a la Cláusula}

El análisis se inicia con una descripción del contexto socio-histórico en que se emite el Último discurso de Salvador Allende, en cuanto este determina las elecciones del emisor en la composición de su discurso así como la interpretación que podamos hacer del mismo. Desde el macro nivel se desciende al nivel lingüístico de la cláusula para analizar los significados que se despliegan en el sistema de la transitividad, en el sistema de modo y los recursos de recontextualización que se hace del actor social Allende en su representación discursiva.

Las elecciones en el sistema de transitividad dan cuenta de cómo el hablante observa su entorno y cómo representa la realidad en su discurso. Para esto elige entre procesos materiales, mentales, relacionales, de comportamiento, verbales y existenciales que posicionan a los actores sociales como distintos tipos de participantes según sea el proceso con el cual se relacionan. Así los participantes podrían ser, por ejemplo, Actor, Sensor, Portador/Identificado, Actuante, Hablante o Existente entre otros. El proceso y el tipo de participantes son categorías léxico-gramaticales que develan la construcción discursiva de la experiencia: por ejemplo, un Actor de Procesos materiales ejecuta típicamente el cambio de energía involucrado en un proceso que refiere a transformaciones en el mundo material; el Sensor de Procesos mentales, por su parte, piensa, siente o percibe los fenómenos, pero no incide en ellos.

Por otro lado, las elecciones en el sistema de modo establecen la manera en que el hablante se posiciona a sí mismo y a sus interlocutores en su texto, principalmente en relación con la interacción que se produce entre ambos y a partir de la cual se puede indagar en las actitudes del emisor en relación a sí mismo y los demás. En el sistema de modo interesan los procesos en cuanto el hablante los gradúa con el uso de finitos modales y expresa juicios en relación con la probabilidad de que algo suceda (Eggins 2002; Halliday 
y Matthiessen 2004; Ghio y Fernández 2008) así como a la obligación o tendencia de los acontecimientos (Eggins 2002; Halliday y Matthiessen 2004).

A la distribución semántica de los roles de los participantes relevada en el análisis de la transitividad y el modo se integra el análisis de las formas en que el actor social Allende se nombra a sí mismo, para lo que se utiliza la propuesta socio-semiótica de van Leeuwen $(1996,2008)$ quien, desde una perspectiva sociológica, sistematiza los tipos de estrategias utilizadas para representar a los actores sociales en el discurso. De acuerdo con esto cuando Allende se incluye en el discurso puede representarse a sí mismo ya sea como agente o paciente de las acciones, de forma personalizada o impersonalizada, como parte de un colectivo o de forma individual, de manera abstracta u objetivada, entre otras posibilidades.

Para el análisis, el discurso se divide en cláusulas en cada una de las cuales se analizan a nivel gramatical los tipos de procesos y los participantes involucrados en ellos. A su vez se determina el modo de las cláusulas y se analizan las formas verbales y cómo estas son determinadas por recursos modales referidos a lo probable, a lo deseable y a la gradualidad. Cuando el Participante de los Procesos es Allende, estos se retoman para analizarlo en relación con las elecciones discursivas para representarse a sí mismo. Así, el análisis propuesto permitirá centrar la atención en el modo en que Allende se posiciona como participante de distintos procesos; la certeza, la probabilidad, la obligación o la tendencia que marcan los acontecimientos; de qué forma se presenta y cómo se nombra a sí mismo.

\section{ConteXto SOCIO-HistóRico del último discurso de AlLENDE}

El proyecto socialista de Allende y su triunfo en las elecciones presidenciales de 1970 implicaba para Chile el camino hacia la revolución socialista por una vía pacífica y constitucional. Sin embargo, los conflictos sociales y los enfrentamientos marcaron el periodo y las Fuerzas Armadas protagonizaron el derrocamiento del gobierno de la Unidad Popular $^{3}$ (UP) en el Golpe de Estado del 11 de septiembre de 1973, hecho que puso fin al gobierno del pueblo: para los trabajadores

el gobierno de la UP parecía permitir, por fin, la realización de demandas largamente esperadas (...) La UP era percibida como un momento distinto, en particular porque el programa de gobierno se definía claramente al servicio de los trabajadores (Rojas 2006: 358).

La oposición, en cambio, "no le dio jamás a Salvador Allende la oportunidad de gobernar: su único afán era destruir el régimen socialista a cualquier costo" (Turrent 2006:

\footnotetext{
${ }^{3}$ Coalición de izquierda conformada por los siguientes partidos políticos: Partido Socialista (PS), Partido Comunista (PC), Movimiento de Acción Popular Unitaria (MAPU), Partido Radical (PR), Acción Popular Independiente (API) y Partido Social Demócrata.
} 
60). Los conflictos sociales se agudizaron y los detractores de la UP lograron que las Fuerzas Armadas derrocaran al presidente Allende al final de su tercer año de gobierno.

El 10 de septiembre de 1970 el presidente Allende había tomado la decisión de anunciar un plebiscito de consulta acerca de la legitimidad de su gobierno, confiado en el alto apoyo desde las clases trabajadoras (Veneros 2003). De esta manera, esperaba calmar el ambiente social beligerante que imperaba en la ciudadanía y acallar las críticas de la oposición hacia su gestión. Sin embargo, este deseo no llegó a concretarse, pues la madrugada del 11 de septiembre fue informado en su residencia de Tomás Moro de que había movimientos de tropas de las Fuerzas Armadas (Verdugo 2003). Ante estos hechos, se desplazó rápidamente al Palacio de La Moneda desde donde intentó resistir la insurrección de las Fuerzas Armadas e informar a la ciudadanía acerca de los acontecimientos.

Aquella mañana se dirigió cinco veces al pueblo. ${ }^{4}$ En cada una de sus intervenciones radiales fue relatando los acontecimientos a la vez que daba instrucciones a los trabajadores para que no abandonaran sus puestos de trabajo y defendieran el gobierno legítimamente elegido. Al avanzar las horas solo le interesaba transmitir serenidad y aconsejar a sus partidarios para que evitaran un enfrentamiento armado. A las 9:10 de la mañana en un discurso breve de un poco más de 6 minutos dirige sus últimas palabras al pueblo de Chile usando la única señal de radio que todavía estaba operativa. Horas más tarde les pide a sus colaboradores que abandonen el palacio de gobierno y él se quita la vida. Las Fuerzas Armadas se toman el poder y dan inicio a una dictadura militar de 17 años (1973-1990).

\section{ANÁLISIS DE LA TRANSITIVIDAD: LA CONSTRUCCIÓN DE LA EXPERIENCIA}

Este discurso se presenta como el último, como la última oportunidad en que el presidente Allende podrá dirigirse al pueblo de Chile de manera masiva a través de la señal de Radio Magallanes, la única radio afín al gobierno que continúa transmitiendo, pues la demás han sido bombardeadas y acalladas por los golpistas. Lo primero que sorprende es la lucidez con que se plantea esta intervención y que le permite al presidente presentir que será su último mensaje, antes del ataque definitivo y antes de su propia muerte (ejemplos 1, 2 y 3). Esta idea se refuerza a lo largo de la alocución en la definición de este último momento tal cual lo concibe el presidente, al mismo tiempo que se presenta a sí mismo en la memoria del pueblo de Chile (ejemplos 4 y 5):

(1) Seguramente, esta será la última oportunidad en que pueda dirigirme a ustedes.

(2) En este momento definitivo, el último en que yo pueda dirigirme a ustedes, quiero que aprovechen la lección.

\footnotetext{
${ }^{4}$ Los mensajes del presidente Allende se trasmitieron a las 7:55, 8:15, 8:45, 9:03y 9:10 A.M. El discurso de las 9:10 es el más conocido y difundido, y el que se analiza en esta ocasión. Este discurso está disponible en audio y texto completo en diversas páginas en internet.
} 
(3) Estas son mis últimas palabras.

(4) Siempre estaré junto a ustedes.

(5) Mi recuerdo será el de un hombre digno que fue leal a la lealtad de los trabajadores.

Esto se complementa con certezas expresadas con acciones materiales asociadas a reacciones frente al ataque que a su vez enfatizan el modo de proceder frente a la certeza de que se trata de la 'última oportunidad' para hablar y actuar:

(6) Ante estos hechos sólo me cabe decir a los trabajadores: ¡Yo no voy a renunciar! ${ }^{5}$

(7) Colocado en un tránsito histórico, pagaré con mi vida la lealtad al pueblo.

(8) El metal tranquilo de mi voz no llegará a ustedes.

El acto traidor de las Fuerzas Armadas de Chile es abordado en dos dimensiones. Por un lado, se presentan las referencias a la traición y, por otro, se insiste en el comportamiento de Allende para ponerlo como modelo y enfatizar más dramáticamente la deslealtad de los golpistas. Las acciones materiales, en este caso, apuntan a hechos que subvierten el orden constitucional y la democracia:

(9) Que sean ellas (mis palabras) un castigo moral para quienes han traicionado el juramento que hicieron.

(10) El capital foráneo, el imperialismo, unidos a la reacción crearon el clima para que las Fuerzas Armadas rompieran su tradición, la que les enseñara el general Schneider y reafirmara el comandante Araya, víctimas del mismo sector social que hoy estará en sus casas esperando con mano ajena, reconquistar el poder para seguir defendiendo sus granjerías y sus privilegios.

Los miembros de las Fuerzas Armadas se alzan en armas contra el pueblo que juraron defender y el almirante Merino y el señor Mendoza traicionan además al presidente y se arrogan una prerrogativa exclusiva del primer mandatario cual es designar al comandante de la Armada y al director general de Carabineros:

(11) El almirante Merino, que se ha autodesignado comandante de la Armada, más el señor Mendoza, general rastrero que sólo ayer manifestara su fidelidad y lealtad al Gobierno, y que también se ha autodenominado director general de carabineros.

La importancia de la referencia al comportamiento de las FFAA y los golpistas es que se refuerza la imagen de Allende y sirve al objetivo de amplificar la conducta leal del presidente.

\footnotetext{
${ }^{5}$ Los recursos que se resaltan en cursiva en los ejemplos corresponden solo a aquellos que ilustran el análisis propuesto, en este caso los tipos de procesos. Los recursos relacionados con el modo y la recontextualización se retoman más adelante en el análisis y se destacan de la misma forma.
} 
Se puede deducir que, a nivel de la transitividad, en el Último discurso de Salvador Allende, predominan las acciones materiales, relacionales y verbales. Los procesos materiales se atribuyen mayoritariamente a la oposición, como acciones transitivas que, en este caso, son acciones materiales con consecuencias siempre negativas: "La Fuerza Aérea ha bombardeado las torres de radio Portales y radio Corporación", mientras que con los procesos relacionales se definen los hechos y los sentimientos: "ellos tienen la fuerza, estaban comprometidos". En la mayoría de los acontecimientos, se destacan las reacciones y los sentimientos frente a la violencia, por eso los procesos relacionales se concentran en la actitud del presidente inscrito en el discurso tanto con el uso de primera persona singular como en la primera persona plural de los posesivos: "la historia es nuestra, siempre estaré con ustedes".

Allende es el actor principal de los procesos, entre los cuales sobresale su rol de Hablante en los procesos verbales, mediante los cuales enfatiza el valor de su mensaje y especifica a quiénes se dirige. Ante esta situación solo le resta hacer un balance de su proceder durante su gobierno, especificar su opción frente al conflicto e indicar a los trabajadores cómo deben comportarse de cara al quebrantamiento del régimen democrático. Los procesos verbales lo sitúan como el participante Hablante y amplifican la importancia que le da a la comunicación con el pueblo:

(12) Seguramente ésta será la última oportunidad en que pueda dirigirme a ustedes. (13) Ante estos hechos sólo me cabe decir a los trabajadores: ¡Yo no voy a renunciar! (14) Me dirijo, sobre todo, a la modesta mujer de nuestra tierra, a la campesina que creyó en nosotros, a la obrera que trabajó más, a la madre que supo de nuestra preocupación por los niños. Me dirijo a los profesionales de la Patria, a los profesionales patriotas que siguieron trabajando contra la sedición auspiciada por los colegios profesionales, colegios de clases para defender también las ventajas de una sociedad capitalista de unos pocos.

Mediante el uso de procesos relacionales de posesión Allende se instaura en el discurso y especifica la naturalización del hecho indiscutido de que las bases de la revolución no pueden ser derribadas, en el momento particularmente violento en que se enmarca su discurso.

(15) Y les digo que tengo la certeza de que la semilla que hemos entregado a la conciencia digna de miles y miles de chilenos no podrá ser segada definitivamente. (16) Trabajadores de mi patria, tengo fe en Chile y su destino.

Frente a las acciones con procesos materiales de la oposición, contrastan las del presidente que consisten en transmitir calma al pueblo que lo escucha, vaticinar la repercusión de estos hechos en la historia con su juicio inexorable y dirigir el accionar del pueblo. Se produce, por lo tanto, un contraste entre las acciones de la oposición y las del presidente, ya que la participación del presidente con el uso también de acciones materiales corresponden a reacciones frente al desarrollo del Golpe de Estado. Por ejemplo: "Colocado 
en un tránsito histórico, pagaré con mi vida la lealtad del pueblo; Ante estos hechos, solo me cabe decirle a los trabajadores: ¡Yo no voy a renunciar!”

\section{ANÁlisis DEL MODO: REFERENCIAS MODALES DE LO PROBABLE Y LO DESEABLE}

Los adjuntos modales con modalización alta marcan la certeza y convicción que caracterizan este último discurso de Salvador Allende. El presidente expresa convicción en cuanto esta será su última intervención transmitida al país. La seguridad de sus palabras supone que las antenas de la única radioemisora afín al gobierno, que aún transmite, serán bombardeadas y que él mismo ya no hablará más, ante los hechos inminentes de su propia muerte.

(17) Seguramente, ésta será la última oportunidad en que pueda dirigirme a ustedes.

(18) En este momento definitivo, el último en que yo pueda dirigirme a ustedes, quiero que aprovechen la lección.

(19) Seguramente Radio Magallanes será acallada, y el metal tranquilo de mi voz no llegará a ustedes.

(20) Estas son mis últimas palabras.

También es categórico y firme al recordar su deber como primer mandatario elegido democráticamente por un periodo de seis años. En este sentido, usa la polaridad negativa y la negación polémica (Ducrot 1999) para subrayar que no hará lo que la oposición espera de él, por el contrario, está dispuesto a defender la legitimidad de su cargo y a respetar hasta el final su compromiso con el pueblo:

(21) Ante estos hechos sólo me cabe decir a los trabajadores: ¡Yo no voy a renunciar! Además, el uso del futuro simple de indicativo implica una modalización alta de significado deóntico.

(22) Colocado en un tránsito histórico, pagaré con mi vida la lealtad al pueblo.

Más adelante retoma el concepto de 'lealtad del pueblo' y también lo destaca con una modalidad de frecuencia alta: el pueblo 'siempre' fue leal con el presidente. Ante esa lealtad, el presidente Allende responde con el mismo compromiso de presencia permanente junto al pueblo:

(23) Trabajadores de mi patria: quiero agradecerles la lealtad que siempre tuvieron.

(24) Siempre estaré junto a ustedes.

Las certezas se manifiestan en relación con lo que es posible esperar en relación con el comportamiento de las Fuerzas Armadas. Allende no duda al respecto y reafirma 
su seguridad, con el uso de adjuntos modales o finitos modales con un grado alto de modalización, para alertar a quienes lo escuchan (ejemplo 25). El uso de formas verbales en futuro simple refleja la convicción de que los trabajadores de Chile seguirán transitando hacia el ideal de sociedad socialista (ejemplos 26 al 29):

(25) Tienen la fuerza, podrán avasallarnos.

(26) Superarán otros hombres este momento gris y amargo en el que la traición pretende imponerse.

(27) La historia los juzgará.

(28) Sigan ustedes sabiendo que, mucho más temprano que tarde, de nuevo se abrirán las grandes alamedas por donde pase el hombre libre, para construir una sociedad mejor.

(29) Tengo la certeza de que mi sacrificio no será en vano, tengo la certeza de que, por lo menos, será una lección moral que castigará la felonía, la cobardía y la traición.

Con estos recursos, el discurso se torna emocional y afectivo, pero firme en la convicción de que su sacrificio es suficiente y que no es necesario que el pueblo se sacrifique con él. Para esto subraya que se trata de la última vez que se dirigirá al país, lo que no había mencionado en los mensajes anteriores.

Este discurso es, sobre todo, un discurso de esperanza reflejada en la elección del futuro simple. En los mismos ejemplos, se aprecia que el futuro encierra un alto grado de certeza y probabilidad respecto de los hechos enunciados a la vez que acentúa la noción de un futuro más bien lejano: superarán otros hombres, en otro tiempo. Al contrario, el uso del futuro perifrástico podría haber asociado su pensamiento a un futuro más inmediato.

El uso de la polaridad negativa también implica una modalidad de grado alto. Por lo tanto, no hay vacilación en relación con la visión del futuro venturoso que Allende prevé para Chile:

(30) Y les digo que tengo la certeza de que la semilla que hemos entregado a la conciencia digna de miles y miles de chilenos no podrá ser segada definitivamente.

(31) Tienen la fuerza, podrán avasallarnos, pero no se detienen los procesos sociales ni con el crimen ni con la fuerza.

\section{ANÁlisis DE LA RECONTEXTUALIZACIÓN: REPRESENTACIÓN DE LOS ACTORES SOCIALES}

Allende refuerza su ethos al definirse a sí mismo como el modelo que se contrapone a los conspiradores: como hombre digno y leal podrá castigar moralmente a los golpistas, porque él está solo, no tiene ya la fuerza de su investidura ni el respaldo de las instituciones del estado, solo su conducta íntegra y honorable servirá de sanción: 
(32) Trabajadores de mi patria: quiero agradecerles la lealtad que siempre tuvieron, la confianza que depositaron en un hombre que solo fue intérprete de grandes anhelos de justicia, que empeñó su palabra en que respetaría la Constitución y la ley, $y$ asi lo hizo.

(33) Por lo menos mi recuerdo será el de un hombre digno que fue leal con la patria.

(34) Tengo la certeza de que mi sacrificio no será en vano, tengo la certeza de que, por lo menos, será una lección moral que castigará la felonía, la cobardía y la traición.

Allende elige la objetivación por somatización que es un procedimiento de referencia metonímica como recurso de impersonalización (van Leeuwen 1996, 2008) para referirse a sí mismo, es decir, se presenta por una parte de su cuerpo, principalmente su voz y su palabra, y por el recuerdo que dejará en la sociedad chilena. Así, la única forma de nominación de sí mismo es la somatización, en todos los demás procesos el hablante está elidido y se recupera en el contexto por la desinencia verbal:

(35) ... el metal tranquilo de mi voz no llegará a ustedes.

(36) Por lo menos mi recuerdo será el de un hombre digno que fue leal con la patria.

(37) Éstas son mis últimas palabras.

Como se puede apreciar en los ejemplos de somatización, el presidente Allende privilegia el uso del adjetivo posesivo de primera persona, como en este otro ejemplo: "trabajadores de $m i$ patria". Este adjetivo aparece también en primera persona plural: "la modesta mujer de nuestra tierra" y como Atributo en cláusulas relacionales, como en: "la historia es nuestra". Así, Allende se posiciona como el centro del discurso, de modo que las señales lingüísticas apuntan al hablante constructor del discurso, destinatario directo de las acciones de fuerza, representante del pueblo y responsable de la mantención de la democracia. Destacan, por tanto, el rol histórico que le corresponde solo a él, la construcción discursiva de su identidad y el discurso centrado en sí mismo y en su compromiso con el pueblo, sobre todo cuando elige usar la primera persona singular explícita en un proceso material enmarcado en las circunstancias del momento histórico complejo al que se enfrenta: "Ante estos hechos, solo me cabe decir a los trabajadores: Yo no voy a renunciar".

El segundo mecanismo importante de impersonalización es la abstracción con la que se realzan principalmente conductas y atributos. Sobresalen las cualidades positivas: primero la lealtad del pueblo y luego la actuación del presidente en relación a la certeza de un futuro mejor y la dignidad de su proceder. En la referencia a sus propias cualidades, Allende se posiciona como el tercero discursivo y habla de sí mismo en tercera persona singular, lo que le permite abordar un alejamiento discursivo que le otorga objetividad al relato de sus cualidades que, además, son mencionadas en pasado. El uso del pretérito indefinido acentúa el aspecto perfectivo de sus acciones, de modo que, enfrentado a la muerte, lo que hace es efectuar un recuento y una valoración de estas: 
(38) ...la confianza que depositaron en un hombre que solo fue intérprete de grandes anhelos de justicia, que empeñó su palabra en que respetaría la Constitución y la ley y asi lo hizo.

(39) Mi recuerdo será el de un hombre digno que fue leal a la lealtad de los trabajadores.

\section{Construcción del Ethos a partir del anÁlisis de transitividad, modo Y RECONTEXTUALIZACIÓN}

Cuando Allende se construye discursivamente como participante de procesos materiales se posiciona como el Actor que asume su rol y su responsabilidad política, como el líder que encabeza el proyecto de un gobierno socialista y revolucionario en Chile y que enfrentado al Golpe de Estado defiende el proyecto de vía democrática y pacífica hacia el socialismo. Se refuerza así el ethos militante con el tópico de la politica como lucha, batalla o epopeya, no solo en relación consigo mismo sino también en una visión de futuro que involucra "a aquellos que serán perseguidos", porque la batalla por la defensa y, sobre todo, por la recuperación de la democracia recién comienza. La lucha también se centra en sí mismo y en sus partidarios, principalmente en la juventud de nuevo entendida la lucha con acciones materiales que modifican el entorno: "me dirijo a la juventud, a aquellos que cantaron, entregaron su alegría y su espíritu de lucha".

El tópico de las convicciones y los sueños se construye con procesos relacionales sobre la certeza de la labor cumplida y la esperanza en que el proceso social iniciado permanecerá en la historia de Chile y seguirá su desarrollo inalterable. A su vez, los procesos relacionales refuerzan la convicción con el uso de la polaridad negativa y la forma verbal en futuro simple; así la negación polémica (Ducrot 1999) contradice en el discurso la intención de los golpistas: "tengo la certeza de que la semilla que entregáramos a la conciencia de miles y miles de chilenos no podrá ser segada definitivamente; la historia es nuestra y la hacen los pueblos". En general, las formas verbales en futuro simple amplifican la certeza acerca del porvenir y sustentan el tópico de las convicciones y los sueños: "la historia los juzgará; superarán otros hombres este momento gris y amargo; mucho más temprano que tarde abrirán de nuevo las grandes alamedas" y el tópico de la heroicidad: "pagaré con mi vida la lealtad del pueblo; mi sacrificio no será en vano". En relación con el tópico del militante como hombre común, recordamos la alusión a sí mismo como tan solo un hombre: "un hombre que solo fue intérprete de grandes anhelos de justicia; un hombre digno que fue leal a la lealtad de los trabajadores".

Allende también es el líder que se presenta como el Hablante productor del discurso, el portavoz del pueblo; por tanto, es el Hablante en los procesos verbales. Es el presidente que se comunica con su pueblo y les informa los acontecimientos del 11 de septiembre, su compromiso con el pueblo y con la vía democrática al socialismo, y la decisión de sacrificar su vida en defensa de la democracia. El discurso se centra en él como portador de la palabra: la palabra que refleja sus sentimientos ("mis palabras no tienen amargura, sino decepción"), la palabra que castiga ("serán ellas el castigo moral"), la palabra de esperanza ("les digo 
que tengo la certeza de que la semilla que entregáramos a la conciencia de miles y miles de chilenos, no podrá ser segada definitivamente"), la palabra serena ("el metal tranquilo de mi voz no llegará a ustedes"), la palabra que no muere ("no importa, lo seguirán oyendo"), la palabra que será su último contacto con el pueblo ("estas son mis últimas palabras"). Tal como aporta Moulian (1998)

todos los discursos de Allende de aquella mańana estuvieron traspasados por la convicción de que representaba el papel de un profeta, que es aquel que habla, grita, gime para que su pueblo (la Patria) pueda discernir entre la verdad y la mentira que los enemigos siembran. Para Allende quedar en silencio fue algo parecido a morir. Resistir era poder hablar, mucho más que disparar en un combate insensato, contra tanques y aviones (Moulian 1998: 25).

La importancia de la palabra y del discurso que sustenta el proyecto político de Allende se reafirma con el recurso de impersonalización y abstracción por somatización (van Leeuwen, 1996, 2008) de modo de centrar la atención en su voz y en el mensaje que desea transmitir al pueblo: su palabra y su voz serena se oponen a la fuerza con que actúan los golpistas, pero tienen la firmeza para pedirle al pueblo que no se sacrifique. En la voz de Allende y en su propia figura se concentra la potencia del mensaje que reivindica el tópico de la heroicidad como el tema central de su discurso.

Es interesante en este punto constatar que el tópico de la política como lucha y el tópico de los sueños y las convicciones se construyen de forma coherente tanto por el presidente como por el pueblo que lo eligió, porque juntos creyeron en una sociedad mejor. Así el ethos discursivo de Allende se reafirma en las características que proyecta en el pueblo, en las mujeres, en los hombres, en los obreros, en la juventud: todos ellos representados en la confianza en el proyecto socialista y en el propio Allende, y representados en el espíritu alegre con que enfrentaron la lucha por la revolución. Sin embargo, el tópico de la heroicidad que cruza todo el discurso se centra solo en el presidente, de modo que el tópico pasa a construir el ethos por sí mismo. El ethos heroico que define a Allende deja de ser un recurso retórico y se convierte, mediante el uso de procesos materiales, en una promesa cumplida: "yo no voy a renunciar, pagaré con mi vida la lealtad del pueblo". Por lo tanto, él como el líder de la revolución, como el representante del pueblo, como el presidente legítimo ofrece su vida en defensa de la democracia y en agradecimiento a la confianza y a la lealtad del pueblo, al mismo tiempo que enfatiza que el sacrificio de un solo hombre es suficiente en estas circunstancias de desigualdad de fuerzas, "el pueblo debe defenderse, pero no sacrificarse; mi sacrificio no será en vano”.

Su papel como líder popular le exigió hacerse responsable de la crisis e impedir un derramamiento de sangre. Evitar la violencia era una parte tan importante de su vía chilena que (...) en ningún momento consideró sacrificar a los trabajadores pidiéndoles que combatieran solos (Veneros 2003: 404). 


\section{Conclusiones}

Como se desprende del análisis gramatical a nivel de cláusula, tanto las elecciones en el nivel transitividad y modo, como los recursos de recontextualización y la correlación de estos con las categorías del ethos sustentan la construcción del ethos heroico.

El ethos discursivo de Allende comparte algunos tópicos del ethos militante (Montero 2007), pero en su particularidad histórica toma el tópico de la heroicidad y lo vuelve central en la construcción de un ethos heroico. Este ethos heroico, como ya dijimos, traspasa la retórica y anticipa el suicidio con que Allende terminaría con su vida un par de horas más tarde de pronunciado el discurso. En conclusión, es el ethos heroico el que se configura discursivamente en el Último discurso de Salvador Allende quien se presenta a sí mismo como el líder que ofrece su vida en defensa de la democracia, de su proyecto de gobierno y de la confianza del pueblo que lo eligió. Materialmente, la configuración discursiva del héroe se reafirma por el acto del suicidio y el discurso se construye como la despedida de quien tienen la certeza de que va a morir, porque la decisión de terminar con su vida es propia y consciente.

La diferencia significativa en relación con el ethos militante descrito por Montero (2007) es que no se trata de una evocación de discursos lejanos, sino que la configuración del ethos militante de Allende se arraiga en la militancia que caracteriza su quehacer político y su período de gobierno desde 1970 a 1973 . Es decir, que el discurso de Allende se enmarca en sus coordenadas espacio-temporales como concomitante al discurso militante que es descrito por Montero (2007) como una reminiscencia en el caso de los discursos de Kirchner. Por otro lado, lo más significativo es que el tópico de la heroicidad visto como uno de los elementos que refuerzan el ethos militante, en el discurso de Allende cobra relevancia como el eje que estructura la representación de sí mismo de manera tal que podemos hablar en propiedad de un ethos heroico. El ethos discursivo en el Último discurso de Salvador Allende predice la actuación del "líder heroico que prefirió la muerte antes que rendirse o traicionar" (Veneros 2003: 455).

En este discurso en particular, el ethos heroico se caracteriza por una fuerte presencia del yo como Actor de procesos materiales, Portador y también Identificado en procesos relacionales y Hablante de procesos verbales. Las acciones materiales lo posicionan como el actor que responde al ataque de las Fuerzas Armadas y se preocupa de no exponer a los trabajadores y al pueblo en su decisión de resistir el ataque y morir en esa defensa si es necesario. En los procesos relacionales se refleja la actitud del presidente frente a los acontecimientos y la convicción de que el proceso de cambios de su gobierno no se detendrá con el golpe de estado. Como hablante de procesos verbales mantiene la comunicación con el pueblo, les transmite calma a los trabajadores y les pide que no se expongan. Quizás el momento más importante se despliega en la elección de un proceso relacional con el cual Allende instala la verdad incuestionable de su recuerdo permanente ("mi recuerdo será el de un hombre digno"), porque para él el suicidio es visto como un acto meramente corpóreo que puede ser trascendido ampliamente por la victoria que impone la presencia definitiva 
en el recuerdo. El presidente se desprende de su existencia material, pero la fortaleza que le confiere la dignidad de sus actos se instala persistente en la memoria del pueblo. Sus últimas palabras evocan la muerte y el sacrificio del héroe como la única forma de ser leal.

En la representación de sí mismo destacan los recursos de impersonalización: objetivación por somatización y abstracción; de esta forma se realza a sí mismo por sus conductas y atributos, además de presentarse mayoritariamente a través de la fuerza y la calma de su voz. Es el líder que actúa en defensa de la democracia y que enfrentado a una lucha desigual toma la palabra para resistir la fuerza desmedida y brutal con un discurso de compromiso y esperanza, y que también se apropia de la palabra para reforzar su liderazgo mediante las instrucciones y el consuelo que transmite al pueblo.

Las elecciones a nivel de modalidad destacan por el uso de adjuntos modales de frecuencia alta y altos grados de certeza lo que refuerza el tono de seguridad con que se proyecta el discurso. No hay duda respecto a la traición de las Fuerzas Armadas, acerca del futuro de la revolución y en cuanto a su opción por el suicidio. Así, la especificación del comportamiento de los golpistas sumado a la descripción de su quehacer político y su conducta intensifican la construcción discursiva de sí como el modelo a seguir. Sostenemos, por tanto, que las elecciones léxico-gramaticales y socio-semánticas confluyen en la construcción del ethos discursivo del Último discurso de Salvador Allende. En definitiva, la palabra de Allende simboliza el honor de un presidente que se comprometió en la defensa de la democracia, de modo que la muerte del presidente en La Moneda se consolida como la personificación de la muerte de la democracia en Chile. El ethos heroico proyecta la imagen simbólica del presidente mártir que encarnó los valores de la democracia y los defendió con su vida.

\section{Obras CITADAS}

Amossy, Ruth. 1999. "El ethos oratorio o la puesta en escena del orador". La argumentación en el discurso (extracto). Traducción Estella Kallay.

Barros, Laurenci y Darling Moreira. 2011. "O Ethos e a Ideologia no Discurso Político de Dilma Rousseff”. Revista Anagrama, Revista Científica Interdisciplinar da Graduação. 4.4: 1-14.

Barthes, Roland. 1993. La aventura semiológica. Barcelona: Paidós.

Berardi, Leda. 1996. "Legitimidad y discurso presidencial. Un análisis de los discursos de los presidentes Eduardo Frei Montalba y Eduardo Frei Ruiz-Tagle”. Revista Chilena de Semiótica 1: 1-19.

Burdach, Ana María y Paula Ross. 2005. "La construcción de la voz del enunciador en el discurso político de Ricardo Lagos, ex Presidente de la República”. ALED 5.1: 97112.

Burgueño, Claudia. 2006. "Relaciones de intertextualidad en discursos políticos presidenciales". Literatura y Lingüística 17: 221- 241. 
Dagatti, Mariano. 2012. "El estadista oculto. El ethos gubernamental en los discursos públicos presidenciales de Néstor Kirchner". Rétor 2.1: 55-93.

Ducrot, Oswald. 1999. El decir y lo dicho. Barcelona: Paidós.

Eggins, Susan. 2002. Introducción a la lingüística sistémica. La Rioja: Universidad de La Rioja.

Ghio, Elsa y Ma Delia Fernández. 2008. Lingüística Sistémico Funcional. Aplicaciones a la lengua espańola. Santa Fe: Universidad Nacional del Litoral.

Gutiérrez Castañeda, Griselda. 1999. La construcción del sujeto de la política. Discurso y producción simbólica. México D. F.: UNAM.

Halliday, Michael. 1978. Language as social semiotic. The social interpretation of language and meaning. London: Edward Arnold. . 1994. An Introduction to Functional Grammar. London: Edward Arnold.

Halliday, Michael y Christian Matthiessen. 2004. An Introduction to Functional Grammar. London: Hodder Arnold.

Joignant, Alfredo. 1998. El gesto y la palabra. Ritos políticos y representaciones sociales de la construcción democrática en Chile. Santiago: Lom Ediciones.

Kress, Gunther, Regina Leite-García y Theo van Leeuwen. 2000. "Semiótica discursiva”. Van Dijk. Comp. El discurso como estructura y proceso (pp. 373-416). Barcelona: Gedisa.

Maizels, Ana Laura. 2014. "Argumentación e imagen de sí de la presidenta argentina Cristina Fernández, en el marco de la crisis con el sector agropecuario”. Rétor 4.2: 153181.

Maingueneau, Dominique. 1996. "El ethos y la voz de lo escrito”. Versión 6: 79-92.

Montero, Ana Soledad. 2007. "Política y convicción. Memorias discursivas de la militancia setentista en el discurso presidencial argentino". ALED 7.2: 91-113.

. 2012. "Los usos del ethos. Abordajes discursivos, sociológicos y políticos". Rétor 2.2: $223-242$

Moulian, Tomás. 1998. Conversación interrumpida con Allende. Santiago: Lom Ediciones.

Oyarzo, Carmen. 2007. "Las razones de los presidentes: Análisis argumental de los discursos presidenciales inaugurales de la transición política de Chile (1990-1994-2000)”. Sociedad Hoy 12: 9-28.

Pereira, Renato. 2012. "Oferecendo uma imagem de si: A (des) construção do Ethos discursivo da Candidata Dilma Rousseff”. Revista Vozes dos Vales: Publicaçóes Acadêmicas, 2. I-10: 1-20.

Quiroz, Beatriz. 2008. “Towards a systemic profile of the Spanish MOOD”. Linguistics and the Human Sciences 4.2: 31-65.

Rojas, Jorge. 2006. "La historiografía, los trabajadores y la Unidad Popular". Zapata. Comp. Frágiles suturas. Chile a treinta años del gobierno de Salvador Allende, (pp. 343-364). México D.F.: Fondo de Cultura Económica.

Roldán, Yasna. 2008. "Salvador Allende: los argumentos de la traición”. Milos. Salvador Allende. Fragmentos para una historia (pp. 221-240). Santiago: Editorial Catalonia. 
.2011. "Salvador Allende: los argumentos del triunfo y los argumentos de la traición”. Revista Austral de Ciencias Sociales 21: 5-22.

. 2014. "Estrategias de denuncia. Análisis del discurso presidencial de Salvador Allende ante la ONU en 1972". Discurso y Sociedad 8.2: 326-349.

Romano, María Belén. 2010. "La construcción del ethos en el discurso inaugural de Cristina F. de Kirchner”. Forma y Función 23.2: 97-125.

Segovia, Pablo. 2012. "La construcción de la imagen de sí mismo y los imaginarios sociales en los discursos de campaña de Ricardo Lagos y Michelle Bachelet: Un acercamiento desde el análisis del discurso". RIPS. Revista de Investigaciones Políticas y Sociológicas 11.2: 81-100.

Sigal, Silvia y Eliseo Verón. 2003. Perón o muerte. Los fundamentos discursivos del fenómeno peronista. Buenos Aires: Eudeba.

Turrent, Isabel. 2006. "El contexto internacional del experimento chileno, 30 años después”. Zapata. Comp. Frágiles suturas. Chile a treinta años del gobierno de Salvador Allende (pp. 59-70). México D.F.: Fondo de Cultura Económica.

Vasilachis de Gialdino, Irene. 1997. La construcción de representaciones sociales. Discurso político y prensa escrita. Un análisis sociológico, jurídico y lingüístico. Barcelona: Gedisa. 2003. Pobres, pobreza, identidad y representaciones sociales. Barcelona: Gedisa.

Van Leeuwen, Theo. 1996. "The Representation of Social Actors". Caldas-Coulthard. Texts and Practices. Readings in Critical Discourse Analysis (pp. 32-70). London: Routledge. . 2008. Discourse and Practice. New Tools for Critical Discourse Analysis. Oxford: Oxford University Press.

Veneros, Diana. 2003. Allende. Un ensayo psicobiográfico. Santiago: Sudamericana.

Verdugo, Patricia. 2003. Allende. Cómo la Casa Blanca provocó su muerte. Santiago: Catalonia.

Vitale, María Alejandra. 2013. "Êthos y legitimación política en los discursos de asunción de la presidente argentina Cristina Fernández de Kirchner". Icono 14 11.1: 5-25. . 2014. "Êthos femenino en los discursos de asunción de las primeras mujeres presidentes de América del Sur: Michelle Bachelet, Cristina Fernández de Kirchner y Dilma Rousseff”. Anclajes XVIII.1: 61-82. 
